\title{
Appropriateness of colonoscopy in Europe (EPAGE II) Surveillance after polypectomy and after resection of colorectal cancer
}

Authors

Institutions
C. Arditi ${ }^{1}$, J.-J. Gonvers ${ }^{2}$, B. Burnand ${ }^{1}$, G. Minoli ${ }^{3}$, D. Oertli ${ }^{4}$, F. Lacaine ${ }^{5}$, R. W. Dubois ${ }^{6}$, J.-P. Vader ${ }^{1}$, S. Schusselé Filliettaz ${ }^{1}$, I. Peytremann-Bridevaux ${ }^{1}$, V. Pittet ${ }^{1}$, P. Juillerat ${ }^{2}$, F. Froehlich ${ }^{2,7}$ and the EPAGE II Study Group ${ }^{8}$ Institutions are listed at the end of article. submitted 17 June 2009 accepted after revision 5 December 2009

\section{Bibliography}

DOI $10.1055 / \mathrm{s}-0028-1119646$ Endoscopy 2009; 41: 209-217 @ Georg Thieme Verlag KG Stuttgart · New York ISSN 0013-726X

\section{Corresponding author} F. Froehlich, MD

Rue Achille-Merguin 44 $\mathrm{CH}-2900$ Porrentruy Switzerland

Fax: +41-32-4662955

florian.froehlich@bluewin.ch
Background and study aims: To summarize the published literature on assessment of appropriateness of colonoscopy for surveillance after polypectomy and after curative-intent resection of colorectal cancer (CRC), and report appropriateness criteria developed by an expert panel, the 2008 European Panel on the Appropriateness of Gastrointestinal Endoscopy, EPAGE II.

Methods: A systematic search of guidelines, systematic reviews and primary studies regarding the evaluation and management of surveillance colonoscopy after polypectomy and after resection of CRC was performed. The RAND/UCLA Appropriateness Method was applied to develop appropriateness criteria for colonoscopy for these conditions.

Results: Most CRCs arise from adenomatous polyps. The characteristics of removed polyps, especially the distinction between low-risk adenomas ( 1 or 2 , small $[<1 \mathrm{~cm}]$, tubular, no highgrade dysplasia) vs. high-risk adenomas (large [ $\geq 1 \mathrm{~cm}$ ], multiple [>3], high-grade dysplasia or villous features), have an impact on advanced

\section{Introduction}

$\nabla$

Cancer of the colon and rectum (colorectal cancer [CRC]) is one of the most common cancers diagnosed in Western countries and the second most common cause of cancer deaths [1,2]. It is generally accepted that most CRCs develop through a continuous process from normal mucosa to benign adenoma and then to carcinoma [3-5]. While nearly all CRCs arise from adenomas, only a small minority of adenomas progress to cancer. Adenomas with advanced features, i.e. $>1 \mathrm{~cm}$ in diameter, with high-grade dysplasia, with $>25 \%$ villous histology, or with invasive cancer, have the highest potential for malignancy. The removal of adenomas, by endoscopic polypectomy or surgical resection, is thus recommended to prevent CRC. After polypectomy, individuals are placed adenoma recurrence. Most guidelines recommend a 3-year follow-up colonoscopy for highrisk adenomas and a 5-year colonoscopy for lowrisk adenomas. Despite the lack of evidence to support or refute any survival benefit for followup colonoscopy after curative-intent CRC resection, surveillance colonoscopy is recommended by most guidelines. The timing of the first surveillance colonoscopy differs. The expert panel considered that $56 \%$ of the clinical indications for colonoscopy for surveillance after polypectomy were appropriate. For surveillance after CRC resection, it considered colonoscopy appropriate 1 year after resection.

Conclusions: Colonoscopy is recommended as a first-choice procedure for surveillance after polypectomy by all published guidelines and by the EPAGE II criteria. Despite the limitations of the published studies, colonoscopy is also recommended by most of the guidelines and by EPAGE II criteria for surveillance after curative-intent CRC resection.

under colonoscopic surveillance to reduce the risk of development of and death from CRC, by detection and removal of new adenomas at surveillance colonoscopy. However, the overall prevalence of adenomas in the population is high ( $~ 30 \%$ at age 50 and $\sim 50 \%$ at age 70 ) and a large number of patients with adenomas are now being identified as a result of the increased use of CRC screening, particularly the dramatic increase in screening colonoscopy, thus placing a huge burden on medical resources applied to surveillance. There is a need for increased efficiency of surveillance colonoscopy practice, to decrease the cost, risk, and overuse of resources for inappropriate examinations.

After diagnosis of CRC, between $66 \%$ and $85 \%$ of cancers can be surgically resected with curative intent [6-8]. After CRC resection, patients are 
also entered into surveillance programs, as approximately onethird of patients experience a recurrence within 5 years of initial surgery [9]. Surveillance strategies are thus employed to detect new polyps, local recurrences (defined as a tumor arising at the original tumor site), distant recurrences, also called metastases, and metachronous cancers (defined as a CRC arising in a bowel site other than that of the index cancer), at a stage when a second curative procedure can be performed. The most effective followup procedure is, however, still unclear. While colonoscopy is considered to be the best tool for detecting CRC, its effectiveness in improving survival in patients with previous CRC has not yet been clearly demonstrated in randomized controlled trials (RCTs). Its appropriateness for surveillance purposes after curative-intent resection of CRC is therefore debated.

In April 2008, a multidisciplinary European expert panel convened in Montreux, Switzerland, to discuss and develop criteria for the appropriate use of colonoscopy. This article presents the literature review on surveillance after polypectomy and after $\mathrm{CRC}$ resection that was provided to the panelists before the panel meeting, to support their ratings of appropriateness of use of colonoscopy in such circumstances, together with the panel results. It is an update of a previous literature review and consideration of appropriateness criteria published in 1999 [10,11].

\section{Methods}

$\nabla$

The literature review process included a systematic search of websites issuing guidelines and of Medline (1997-February 2008) to select published guidelines, systematic reviews, and primary studies assessing the use of colonoscopy for surveillance after endoscopic resection of colonic polyps and for surveillance after curative-intent resection of CRC. With the exception of certain relevant articles, the literature published before 1997 is presented in the previous literature review $[10,11]$.

The targeted patients are individuals placed under colonoscopic surveillance after polypectomy or curative-intent resection of CRC, to reduce the risk of development of and death from CRC, by removal of new lesions at surveillance colonoscopy

The application of the RAND/UCLA Appropriateness Method is described in detail in a companion article in this issue [12]. Briefly, this process is a formal explicit expert panel method that allows classification of each indication into one of the following categories of appropriateness: "inappropriate," "uncertain," “appropriate," "appropriate and necessary” (i.e. mandating colonoscopy). To simplify the graphical presentation of the appropriateness results, these four categories were consolidated into two clusters: "Appropriate" (comprising two categories: appropriate, appropriate and necessary), and "Not appropriate" (comprising two categories: inappropriate, uncertain). In addition to simplification and enhanced clarity of presentation, the rationale was that in many instances of a non-appropriate scenario, whether it be uncertain or inappropriate, it was especially important that the decision for not proposing the colonoscopy should be discussed and shared with the patient; this simplified representation would help here. All clinical indications and their ratings are available on the EPAGE website (www.epage.ch).

\section{Results: Literature review}

$\nabla$

\section{Surveillance after polypectomy}

The objective of postpolypectomy surveillance is to reduce the risk of development of and death from a CRC, by detecting and removing metachronous adenomas and cancers. Colonoscopy is the first-choice procedure for postpolypectomy surveillance as it has been shown to be more sensitive than barium enema in detecting recurrence and permits resection of polyps [13].

Incidence of adenomas, advanced adenomas and CRC after polypectomy, according to adenoma characteristics at index colonoscopy

Diagnostic yield of surveillance colonoscopy after polypectomy, as reported in studies published since 1997, is shown in Table e1. Results from the National Polyp Study (NPS) and the Funen Adenoma Study were also included, as these studies are major references for guidelines. Recurrence rates vary greatly between studies due to differences in patient characteristics at baseline, duration of follow-up, patient compliance, inclusion criteria, and quality of initial colonoscopy and polypectomy.

In most cases, the recurrence rate varies according to the baseline adenoma characteristics. Indeed, various different adenoma characteristics at index colonoscopy have been associated with subsequent advanced adenomas at surveillance colonoscopy in various RCTs and cohort studies published since 1997, summarized in Table e2. Two characteristics at index colonoscopy were reported in most studies as significantly increasing the risk of advanced adenomas at surveillance colonoscopy: 3 or more adenomas [14-20] and polyp size $>1 \mathrm{~cm}[17-19,21,22]$. Two studies reported significantly higher rates of recurrence with proximal polyp location at index colonoscopy $[15,22]$. Histology findings (a tubulovillous/villous component or high-grade dysplasia) were not a significant predictor of advanced adenomas in the studies reported here, except in the study on predictors of advanced rectal adenomas [23]. One study also found higher rates of advanced adenomas among patients with high-grade dysplasia at baseline (17.4\%) compared with patients with small tubular adenomas (6.1\%) [17]. In another study [21], adenomas with tubulovillous and villous components at baseline were significantly associated with villous adenomas at follow-up (odds ratio [OR] 3.7, 95\% CI 1.3-10.2 and OR 32.0, 95\% 5.3-191.7, respectively). Increasing age [21,22,24,25] and male gender [15, 19,21,22] also increased the risk of subsequent adenomas. A previous history of polyps before baseline polypectomy was also associated with an increased risk of subsequent adenomas [15,22,24]. One study reported that patients with a family history of CRC had a higher recurrence rate for advanced adenomas at surveillance [19]. Finally, one RCT reported a higher recurrence rate if the initial colonoscopy was incomplete [16].

Results from the meta-analysis of Saini et al. [26] on risk factors for recurrence of advanced adenomas showed that patients with $\geq 3$ adenomas at index colonoscopy were more likely to have recurrent advanced adenomas than patients with 1 or 2 adenomas ([relative risk] RR 2.52, 95\% CI 1.07-5.97), as were patients with adenomas with high-grade dysplasia (RR 1.84, 95\% CI 1.06-3.19) compared with patients with low-grade dysplasia.

Compared with patients who were free of polyps, patients with 1 or 2 tubular adenomas of $<1 \mathrm{~cm}$ in size at baseline did not have a statistically higher rate of advanced adenomas at follow-up [17]. However, patients with 3 or more small adenomas or with ade- 
nomas $>1 \mathrm{~cm}$, with a villous component, or high-grade dysplasia, had a significantly higher risk of advanced adenomas.

Nonpolypoid adenomas (also called nonpolypoid [i.e. flat and depressed] colorectal neoplasia [NP-CRN]), originally thought to exist primarily in Japan, have now been described throughout the world, and represent between $6 \%$ and $37 \%$ of adenomas found at colonoscopy in recent studies [27-31]. Left undetected, these flat lesions may evolve into advanced cancer within a few years [32]. Nonpolypoid colorectal adenomas were more likely to contain carcinoma (OR 9.78; 95\% CI 3.93-24.4) than polypoid lesions, irrespective of size [31]. In particular, the depressed type of NP-CRN has the highest risk of containing high-grade dysplasia or invasive adenocarcinoma [31]. However, the risk of advanced adenomas at follow-up is unknown for patients with flat and depressed adenomas, as most studies did not distinguish patients with such lesions at baseline. The high prevalence of nonpolypoid adenomas [31], which are more difficult to detect, once again emphasizes the need for high-quality colonoscopy.

\section{Colonoscopic surveillance intervals after polypectomy}

While, for ethical reasons, no randomized trial has compared endoscopic surveillance versus no surveillance, a number of RCTs have evaluated the impact of different time intervals between follow-up colonoscopies after polypectomy on the incidence of subsequent advanced adenomas and CRCs.

The National Polyp Study compared follow-up colonoscopy at 1 and 3 years after polypectomy versus at 3 years only. As the incidence of advanced adenomas and cancers was similar in the two groups after 3 years of follow-up, the authors recommended surveillance at a 3-year interval for most patients after polypectomy [20]. The Funen Adenoma Study compared follow-up colonoscopies at 2 and 4 years to 4 years only for patients with pedunculated and small sessile colorectal adenomas $[16,33]$. The cumulative risk of advanced adenomas did not differ between the two groups after 4 years of follow-up, nor at the end of the longterm follow-up period (up to 20 years). On the other hand, while the CRC prevalence rate was similar between the two groups after 4 years of follow-up, the relative risk for CRC was higher for patients in the 4-year interval group at the end of the long-term follow-up period (RR 6.22, 95\% CI 1.06-117.48). In contrast to their initial conclusions stating that the first control colonoscopy may be postponed until 4 years after resection, the authors concluded from the long-term results that the 2-year interval may be safer, although the risk of complications could be higher. In another trial with a shorter follow-up period (6 years) and fewer patients, the same authors compared follow-up colonoscopies every year versus every 2 years for patients with sessile adenomas $>5 \mathrm{~mm}$ and villous adenomas (high-risk group) [33]. The risk of advanced adenomas and CRC did not significantly differ between the two groups, although more advanced cancers were detected in the 2-year interval group suggesting that the 2-year interval may be too long.

Another RCT compared six surveillance strategies at 1-, 2-, or 5year intervals using either flexible sigmoidoscopy or colonoscopy, after stratification for high-risk and low-risk of recurrence [34]. After 12 years of follow-up, recurrence rates were low and occurred mostly in high-risk patients (adenoma $>2 \mathrm{~cm}$, severe dysplasia, $>2$ adenomas, or family history of CRC in $\geq 2$ first-degree relatives) (RR 1.82, 95\% CI 1.2-2.9). The number of cancers observed (4) was also lower than expected (9.1). The authors concluded that follow-up endoscopy can safely be reduced to 5- year intervals for the majority of patients, using colonoscopy rather than flexible sigmoidoscopy.

Finally, in Lieberman and colleagues' cohort study on CRC screening by colonoscopy, patients with small adenomas $(<1 \mathrm{~cm})$ at baseline were randomly assigned to surveillance at 2 and 5 years versus 5 years only [17]. Although the rate of advanced adenomas did not differ between the groups at 5.5 years of follow-up, results should be interpreted with caution due to the short followup period and potential selection bias due to the study design.

In a recent case-controlled study [35], individuals with a history of polypectomy had a significantly lower risk of CRC up to 5 years after polypectomy, even after removal of high-risk polyps, compared with individuals without previous endoscopy. However, a nonsignificant increase in risk of CRC was found between 6 and 10 years after polypectomy, which did not support further extension of surveillance intervals. Results from a multivariate analysis of a cohort study of patients after polypectomy showed that patients with no family history of CRC and only small $(<1 \mathrm{~cm})$ tubular adenomas (low-risk group) had a very low risk of advanced adenomas compared to all other patients (high-risk group) [19]. The authors recommend a 10-year interval for surveillance for the low-risk group and a 3-year interval for the high-risk group, based on the estimation that $10 \%$ will develop advanced adenomas after 10 years in the low-risk group and after 3 years in the high-risk group. In a recent analysis of the Polyp Prevention Trial [36], the 4-year risk for advanced adenomas was higher for individuals with an advanced and/or proximal adenoma at baseline (9\%), compared with $5 \%$ for nonadvanced adenomas or distal adenomas. This difference is statistically significant but may not be clinically important. Patients with 3 or more nonadvanced adenomas had the same $6 \%$ overall risk for advanced adenoma as the entire cohort.

Impact of initial polypectomy and colonoscopic surveillance on CRC risk and mortality

It is difficult to distinguish the impact of initial polypectomy on CRC risk and mortality from the impact of colonoscopic surveillance, as the study populations in most postpolypectomy studies were subjected to both polypectomy and colonoscopic surveillance. In Table e3, the studies presented evaluate the impact of polypectomy and colonoscopic surveillance on CRC incidence and on mortality from CRC $[5,21,24,34,37-42]$.

A number of observational studies, particularly the National Polyp Study, have shown that the removal of adenomatous polyps and subsequent surveillance significantly decrease the incidence of CRC compared with that expected in the general population $[5,21,37,38]$. On the other hand, other observational studies found no significant difference between the observed and expected incidence of CRC $[24,40,41]$ and one populationbased study found a higher than expected incidence of CRC in patients with adenomas [39]. Results from this study should, however, be interpreted with caution as no formal colonoscopic surveillance schedule was in place and it was not known whether adenomas were removed. Differences in adenoma characteristics at baseline may explain different risk estimates for CRC, as patients with large adenomas are at higher risk.

The impact of polypectomy and colonoscopic surveillance on CRC mortality was reported in one study only, based on the analysis of several studies with various follow-up intervals [38]. Results showed that in a population of patients with all types of adenomas, mortality from CRC was significantly reduced (RR 0.12, 95\% CI $0.03-0.36$ ). While the overall mortality was not significantly 
reduced (RR 0.93, 95\% CI 0.86-1.01), a significant small reduction was found in women (RR 0.86, 95\% CI 0.74-0.99).

\section{Guidelines on the use of colonoscopy for surveillance after} polypectomy

Table e4 presents the recommendations from representative guidelines on endoscopic follow-up after polypectomy [19,4348]. These guidelines are consolidated in Fig.e1. These new guidelines differ from previous postpolypectomy guidelines published before 1997 in that baseline adenoma characteristics play a major role in determining appropriate postpolypectomy surveillance intervals. Patients are stratified into lower-risk and higher-risk groups with a specific surveillance interval. In summary, the next colonoscopic surveillance is recommended at 3 years for patients with high-risk adenomas (large [ $\geq 1 \mathrm{~cm}$ ], multiple [ $\geq 3$ ], high-grade dysplasia, villous features), and at 5 years for patients with low-risk adenomas ( 1 or 2 , small $[<1 \mathrm{~cm}]$ tubular adenomas with no high-grade dysplasia).

Patients with small $(<1 \mathrm{~cm})$ and fewer than 5 rectosigmoid hyperplastic polyps are considered to have a normal colonoscopy and therefore not at increased risk for CRC. However, for patients with large $(\geq 1 \mathrm{~cm})$ or numerous $(\geq 5)$ hyperplastic polyps, follow-up colonoscopy is recommended at 5 years [43]. Patients with hyperplastic polyposis, $\geq 5$ hyperplastic polyps proximal to the sigmoid colon, 2 of which are $>1 \mathrm{~cm}$ in diameter, or any number of hyperplastic polyps with a first-degree relative with hyperplastic polyposis, or $>30$ hyperplastic polyps of any size distributed throughout the colon [49], should probably be offered annual colonoscopy [45]. Literature is scarce in this field.

Extremely vigilant follow-up, with initial colonoscopy intervals of 3-6 months, is warranted for sessile adenomas $(>2-3 \mathrm{~cm})$ $[44,48]$ since $28 \%$ recur or persist after piecemeal resection, and $17 \%$ later degenerate into carcinoma despite apparently complete removal [50].

The baseline colonoscopy needs to be of high quality for the baseline adenoma characteristics to be suitable for use in planning surveillance intervals, as baseline colonoscopy without a good clearing of the colon places the patient at increased risk of subsequent neoplastic findings. According to the US Multi-Society Task Force, a high-quality colonoscopy reaches the cecum in over 95\% of cases, has little fecal residue, and has a minimum withdrawal time from the cecum of $6-10$ minutes [51].

\section{Surveillance after curative-intent CRC resection}

Colonoscopic surveillance after CRC resection aims at improving survival by the early detection of asymptomatic recurrences of the initial cancer in the bowel (anastomotic or intraluminal recurrence), metachronous CRC, and adenomatous polyps, as early detection increases the chance of successful resection of local recurrence or metachronous cancer [52]. The proportion of patients who undergo a second curative resection has increased in the last 20 years [53]. Curative reoperation is performed more often for metachronous cancers $(67 \%-86 \%)$ than for local recurrences $(7 \%-22 \%)$ [54]. However, as local recurrence and metachronous CRC are relatively infrequent, it has been considered that colonoscopy alone is of limited usefulness $[55,56]$ and other tests should form part of a surveillance program.

Recurrence, metachronous cancer and adenomatous polyps As the incidence of recurrences and new tumors after CRC resection is an important factor in determining whether and when colonoscopic surveillance should take place, some evidence per- taining to these rates, and to risk factors for recurrence and new tumors, is briefly presented. Studies published between 1997 and February 2008 report low rates of intraluminal recurrence and metachronous CRC that are detected by surveillance colonoscopy (1\%-9\%) [54,57-72] (see Table e5). The rate of metachronous CRC is even lower when perioperative colonoscopy is performed to clear the colon of synchronous lesions $[57,63,67]$. In a recent population-based study using a cancer registry as the source of information [73], the cumulative rate of metachronous CRC was $1.8 \%(95 \% \mathrm{CI} 1.5-2.2)$ at 5 years, and $3.4 \%(95 \% \mathrm{CI} 2.9-$ 4.0 ) at 10 years, and individuals with previous CRC were at greater risk of developing a new CRC (standardized incidence ratio [SIR] 1.5 [1.3-1.7]). Rates of adenomatous polyps, also reported in Table e5, are higher (between 7\% and 34\%) [59,60,64-70], especially in the presence of synchronous polyps at perioperative colonoscopy [57].

Most recurrences occur within 2 years of initial surgery $[52,74-$ $79]$, while few recurrences $(1 \%-12 \%)$ occur after 5 years $[52,80-$ $82]$. Various risk factors have an impact on rates of recurrence. A more advanced stage of the primary tumor at diagnosis is associated with a higher local recurrence rate [83-86] (Table e6a-c). In addition, cancers located at the rectosigmoid junction are more prone to local recurrence than tumors of the right or left colon, and left-sided primary tumors recur more often than right-sided ones; poorly-differentiated tumors, ulcerating tumors, and tumors $>3 \mathrm{~cm}$ also showed a higher incidence of recurrence $[52,74,75,80,81,83,85]$. Finally, recurrence occurs more often in rectal cancer patients than in colon cancer patients $[84,85]$. Risk factors for metachronous cancers include synchronous cancer and polyps along with index cancer at initial resection, an initial tumor located in the proximal colon, and hereditary nonpolyposis colorectal cancer (HNPCC) $[87,88]$.

\section{Effectiveness of colonoscopy for surveillance after curative} intent resection of CRC

The mean yield of surveillance colonoscopy was reported to be $7.6 \%$ for colon cancer (range $1 \%-25 \%$ ) and $17.2 \%$ for adenomatous polyps (range $6 \%-40 \%$ ) [89]. In the meta-analysis performed by the US Multi-Society Task Force [90], 157 colonoscopies were needed to detect one metachronous cancer.

No randomized trial was found evaluating whether surveillance colonoscopy alone improves patient outcome. In a case-controlled study [91], surveillance endoscopy (colonoscopy or flexible sigmoidoscopy) was not associated with improved CRC survival (OR 1.01, 95\% CI 0.95-1.06). However, the study included only patients $>65$ years old, with many competing causes of death, which may have removed any evidence of benefit by surveillance endoscopy. Results from a retrospective cohort study [67] showed that colonoscopic surveillance was associated with improved 5-year survival compared with no surveillance $(76.8 \%$ vs. $52.2 \%, P<.0001)$ and that the risk of mortality was decreased by $42 \%$ (hazard ratio [HR] $0.58,95 \% \mathrm{Cl} 0.44-.075$ ). Another retrospective cohort study of veterans also found that the risk of mortality decreased by $43 \%$ (HR $0.57,95 \% \mathrm{CI} 0.51-0.64)$ in patients who had at least one follow-up colonoscopy [92].

Five RCTs were published between January 1997 and February $2008[54,68,77,79,93]$ comparing standard follow-up programs with intensive programs, including colonoscopy along with other tests, in addition to the two RCTs published before $1997[94,95]$ (Table e7). A significant improvement in overall survival in the intensive follow-up group was reported in only two RCTs $[79,93]$, while the other trials failed to show any benefit from an 


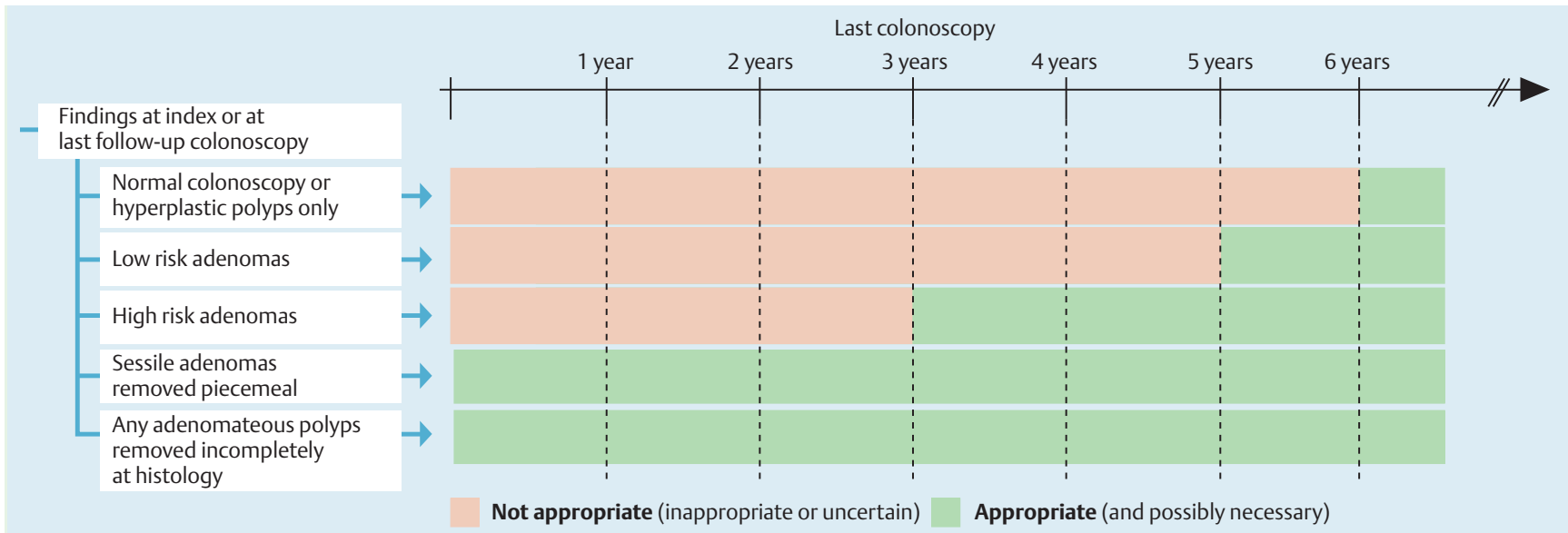

Fig. 2a Appropriateness ratings of clinical indications for performing colonoscopy for surveillance after polypectomy (simplified decision tree). Copyright ( 2008 IUMSP/CHUV, Lausanne, Switzerland - EPAGE II.

intensive follow-up regimen on survival rate $[54,68,77,94,95]$. This absence of benefit may be due to a lack of statistical power, as these trials included between 100 and 600 patients only, and due to the small proportion of patients with a potentially curable recurrence. In one of these RCTs [68], yearly colonoscopy failed to detect any asymptomatic local recurrence, while in another trial [77], yearly colonoscopy detected $44 \%$ of resectable tumor recurrences. Six systematic reviews and meta-analyses of follow-up studies were also identified in the literature published since 1997 [76, 96-100]. Results from the two meta-analyses published in 2007 [97] suggested that there is an overall survival benefit with intensive follow-up of patients after curative surgery for CRC, and that more curative reoperations for recurrences were performed in the intensive follow-up groups, leading to better survival. The specific role of endoscopic surveillance in improving survival cannot, however, be estimated from these studies. In the subgroup analyses of one of the meta-analyses [100], surveillance programs including colonoscopy and serum carcinoembryonic antigen (CEA) measurement showed a significant impact on overall mortality.

\section{Guidelines on the use of colonoscopy for surveillance after curative-intent resection of CRC}

Table e8 presents a summary of the recommendations from representative guidelines on endoscopic follow-up after resection of CRC $[43,46,47,90,96,101-105]$. Despite the lack of evidence to support or refute any survival benefit of colonoscopic follow-up, surveillance colonoscopy is recommended by all guidelines. According to the American guidelines [90], candidates for surveillance colonoscopy are patients who undergo a curative-intent resection of colon and rectal cancers of all stages. Guidelines on the timing of the first surveillance colonoscopy after the perioperative colonoscopy differ. According to some guidelines $[90,104,105]$, the first surveillance colonoscopy should be performed 1 year after resection (or 1 year following perioperative colonoscopy), based on the high incidence of metachronous lesions within the first 2 years after resection. The timing of subsequent colonoscopies if results from the previous one are normal varies from 3 to 5 years according to the different guidelines. The interval should be reduced if adenomas are found at colonoscopy [90].
Table 9 Definitions of terms used to characterize clinical indications for the use of colonoscopy in surveillance after polypectomy and after resection of colorectal cancer (CRC).

\begin{tabular}{|c|c|}
\hline Term & Definition \\
\hline $\begin{array}{l}\text { Low-risk } \\
\text { adenomas }\end{array}$ & $\begin{array}{l}\text { All of the following: } \\
\text { No more than } 2 \text { adenomas } \\
\text { Size }<1 \mathrm{~cm} \\
\text { Tubular histology } \\
\text { No high-grade dysplasia } \\
\text { No family history in first-degree relative }\end{array}$ \\
\hline $\begin{array}{l}\text { High-risk } \\
\text { adenomas }\end{array}$ & $\begin{array}{l}\text { Any of the following: } \\
\text { Villous or tubulovillous histology or serrated } \\
\text { adenoma (any size, number or grade of dysplasia) } \\
\text { Size } \geq 1 \mathrm{~cm} \\
\text { Multiple adenomas ( } \geq 3 \text { ) } \\
\text { Large sessile adenoma } \\
\text { High-grade dysplasia }\end{array}$ \\
\hline
\end{tabular}

\section{EPAGE II appropriateness criteria \\ $\nabla$}

\section{Surveillance after polypectomy}

Out of 463 indications, 77 pertained to colonoscopic surveillance after polypectomy. The proportions of indications related to colonoscopic surveillance considered appropriate, uncertain, or inappropriate were $56 \%, 7 \%$, and $38 \%$ respectively. Disagreement between panelists occurred in only $3 \%$ of cases. The panel deemed 36 indications (47\%) to be necessary (mandating colonoscopic surveillance). $\odot$ Fig. 2 a shows the overall color-coded panel results as a simplified dichotomy: "Not appropriate" (inappropriate or uncertain), versus "Appropriate" (appropriate and possibly necessary). Fig. e2b shows appropriateness criteria in more detail, with the full range of categories: inappropriate, uncertain, appropriate, and necessary (mandating colonoscopic surveillance). Terms used for the definition of these scenarios are listed in $\odot$ Table 9.

When the index or follow-up colonoscopy revealed hyperplastic polyps or the follow-up examination was normal, follow-up colonoscopy was considered appropriate at 5.5 years.

For low-risk adenomas at index or at last follow-up colonoscopy, the next follow-up colonoscopy was considered appropriate at 5 years and necessary after 5.5 years. For high-risk adenomas, follow-up colonoscopy was considered appropriate and necessary at 3 years after the index or the last follow-up colonoscopy. For sessile adenomas removed piecemeal, follow-up colonoscopy 


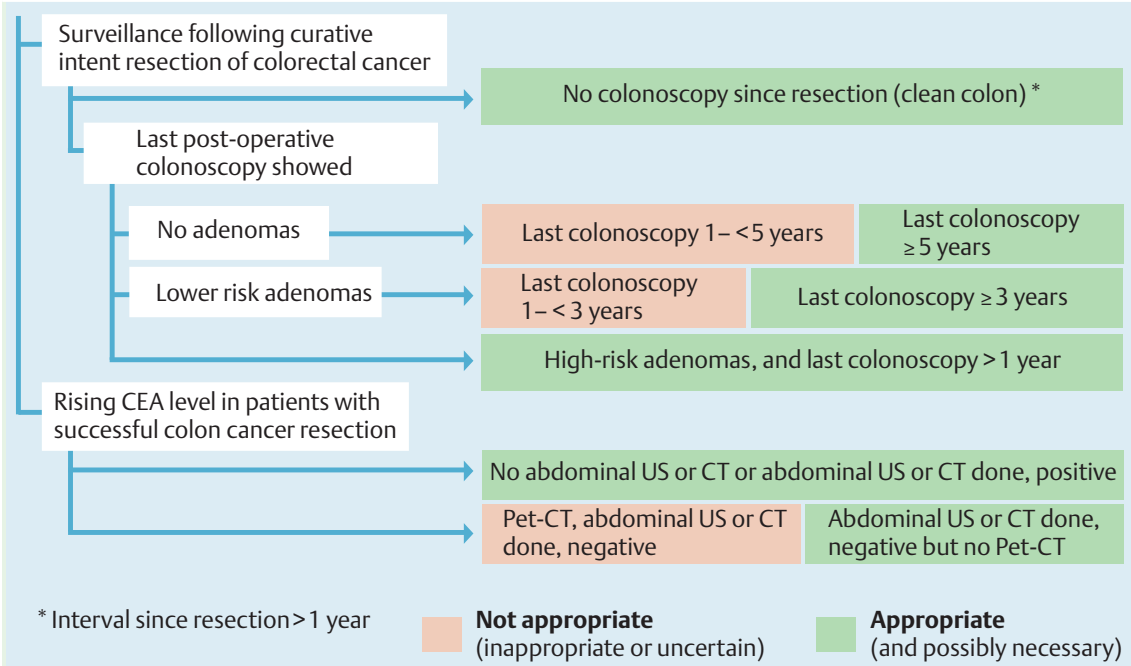

Fig. 3a Appropriateness ratings of clinical indications for performing colonoscopy for surveillance after curative-intent resection of colorectal cancer (CRC) (simplified decision tree). Copyright (c) 2008 IUMSP/CHUV, Lausanne, Switzerland - EPAGE II. was considered appropriate and necessary within the first 9 months following the index colonoscopy. For any adenomatous polyp incompletely removed histologically, follow-up colonoscopy was considered appropriate within 9 months of the incomplete resection and necessary ater 9 months.

\section{Surveillance following curative-intent CRC resection}

Out of 463 indications, 16 pertained to colonoscopic surveillance after curative-intent resection of CRC. The proportions of indications for colonoscopic surveillance considered appropriate, uncertain, or inappropriate were $63 \%, 25 \%$ and $12 \%$, respectively. Disagreement between panelists occurred in $13 \%$ of cases. Six indications $(37.5 \%)$ were deemed necessary (mandating colonoscopic surveillance) by the panel. $\$$ Fig. 3 a shows the overall color-coded panel results as a simplified dichotomy: "Not appropriate" (inappropriate or uncertain), versus "Appropriate" (appropriate and possibly necessary). Fig. e3b shows appropriateness criteria in more detail, with the full range of categories: inappropriate, uncertain, appropriate, and necessary (mandating colonoscopic surveillance). Terms used for the definition of these scenarios are listed in $\bullet$ Table 9.

When there had been no colonoscopy since resection but the colon was clean at the time of surgery, follow-up colonoscopy was considered appropriate 1 year after resection and necessary after 3 years. When the last postoperative colonoscopy revealed no adenoma, the next colonoscopy should be scheduled after 5 years. If the last postoperative colonoscopy revealed low-risk adenomas, colonoscopy was appropriate after 3 years and necessary after 5 years. If the last postoperative colonoscopy revealed high-risk adenomas, a follow-up colonoscopy after 1 year was appropriate and necessary. If the CEA level was shown to be rising, a colonoscopy was only appropriate if abdominal ultrasound or computed tomography (CT) scan were negative and there had been no positron emission tomography-computed tomography (PET-CT) scan.

\section{Conclusions}

$\nabla$

Most, but not all, of the available evidence has shown that polypectomy followed by colonoscopic surveillance is effective in decreasing the incidence of and mortality from CRC. There is also a fair amount of evidence that the characteristics of removed polyps at the index colonoscopy, especially whether low-risk vs. high-risk adenomas, has an impact on the finding of advanced adenomas at surveillance colonoscopy. In accordance with the literature review and clinical practice guidelines, the expert panel recommended a 3-year interval for the high-risk group and a 5year interval for the low-risk group.

The available evidence from RCTs and systematic reviews for surveillance after CRC resection indicates a minor improvement of survival rate with intensive follow-up including colonoscopy. However, the specific role of colonoscopy in improving patient outcome cannot be clearly determined based on available studies. Nevertheless, published guidelines recommend colonoscopy in a surveillance program after curative-intent resection of a CRC. Colonoscopy is considered specifically useful for the detection of metachronous cancers, even though rates are low.

In surveillance after CRC resection, the expert panel considered colonoscopy appropriate after 1 year. The recommended interval for subsequent colonoscopies was 5 years when results are normal, but shorter ( 3 years) in the presence of low-risk adenomas and after $1-3$ years in the presence of high-risk adenomas.

\section{Acknowledgments}

$\nabla$

The authors gratefully acknowledge the selfless commitment and invaluable contribution of the expert panel members, who made this project possible: Lars Agréus (SE), Christoph Beglinger $(\mathrm{CH})$, Peter Bytzer (DK), Michel Delvaux (FR), Volker F. Eckardt (DE), Peter D. Fairclough (UK), François Lacaine (FR), Olivier Le Moine (BE), Vicente Lorenzo Zúñiga Garcia (ES), Giorgio Minoli (IT), Mattijs E. Numans (NL), Daniel Oertli (CH), John O'Malley (UK), Alastair Windsor (UK). The authors warmly thank Susan Giddons for her invaluable assistance in the administration of the expert panel process, as well as in the meticulous preparation of the manuscripts.

This work was supported by a grant from the Loterie Romande (Switzerland).

\section{Competing interests: None}




\section{Appendix: The EPAGE II Study Group \\ $\nabla$}

See page 205 .

\section{Institutions}

1 Healthcare Evaluation Unit, Institute of Social and Preventive Medicine (IUMSP), Centre Hospitalier Universitaire Vaudois and University of Lausanne, Lausanne, Switzerland

2 Department of Gastroenterology and Hepatology, Centre Hospitalier Universitaire Vaudois and University of Lausanne, Lausanne, Switzerland

3 Gastroenterologist, Como, Italy

4 Department of Surgery, University of Basle, Basle, Switzerland

5 Service de chirurgie digestive, Hôpital Tenon, Paris, France

6 Cerner LifeSciences, Beverly Hills, USA

7 Department of Gastroenterology, University of Basle, Basle, Switzerland

8 The EPAGE II Study Group

\section{References}

1 Ferlay J, Autier P, Boniol $M$ et al. Estimates of the cancer incidence and mortality in Europe in 2006. Ann Oncol 2007; 18: 581 -592

2 Jemal A, Siegel $R$, Ward E et al. Cancer statistics, 2007. CA: Cancer J Clin 2007; 57: 43-66

3 Muto T, Bussey HJ, Morson BC. The evolution of cancer of the colon and rectum. Cancer 1975; 36: 2251-2270

4 Stryker SJ, Wolff BG, Culp CE et al. Natural history of untreated colonic polyps. Gastroenterology 1987; 93: 1009-1013

5 Winawer SJ, Zauber AG, Ho MN et al. Prevention of colorectal cancer by colonoscopic polypectomy. The National Polyp Study Workgroup. N Engl J Med 1993; 329: 1977 - 1981

6 Ekman CA, Gustavson J, Henning A. Value of a follow-up study of recurrent carcinoma of the colon and rectum. Surg Gynecol Obstet 1977; 145: $895-897$

7 Faivre-Finn C, Bouvier-Benhamiche AM, Phelip JM et al. Colon cancer in France: evidence for improvement in management and survival. Gut 2002; 51: 60-64

8 Tornqvist A, Ekelund G, Leandoer L. Early diagnosis of metachronous colorectal carcinoma. Aust N Zealand J Surg 1981; 51: 442 - 445

9 Kapiteijn E, Marijnen CA, Nagtegaal ID et al. Preoperative radiotherapy combined with total mesorectal excision for resectable rectal cancer. $\mathrm{N}$ Engl J Med 2001; 345: 638-646

10 Bochud M, Burnand B, Froehlich F et al. 12. Appropriateness of colonoscopy: surveillance after polypectomy. Endoscopy 1999; 31: 654-663

11 Bochud M, Burnand B, Froehlich F et al. 13. Appropriateness of colonoscopy: surveillance after curative resection of colorectal cancer. Endoscopy 1999; 31: 664-672

12 Juillerat P, Peytremann-Bridevaux I, Vader JP et al. Appropriateness of colonoscopy in Europe. Presentation of EPAGE II methodology, general results, and analysis of complications. Endoscopy 2008; 41: 240-246

13 Winawer SJ, Stewart ET, Zauber AG et al. A comparison of colonoscopy and double-contrast barium enema for surveillance after polypectomy. National Polyp Study Work Group. N Engl J Med 2000; 342: $1766-1772$

14 Avidan B, Sonnenberg A, Schnell TG et al. New occurrence and recurrence of neoplasms within 5 years of a screening colonoscopy. Am J Gastroenterol 2002; 97: 1524-1529

15 Bonithon-Kopp C, Piard F, Fenger C et al. Colorectal adenoma characteristics as predictors of recurrence. Dis Colon Rectum 2004; 47: $323-$ 333

16 Jorgensen $O D$, Kronborg $O$, Fenger $C$. A randomized surveillance study of patients with pedunculated and small sessile tubular and tubulovillous adenomas. the Funen Adenoma Follow-up Study. Scand J Gastroenterol 1995; 30: 686-692

17 Lieberman DA, Weiss DG, Harford WV et al. Five-year colon surveillance after screening colonoscopy. Gastroenterology 2007; 133: 1077-1085

18 Noshirwani KC, van Stolk RU, Rybicki LA, Beck GJ. Adenoma size and number are predictive of adenoma recurrence: implications for surveillance colonoscopy. Gastrointest Endosc 2000; 51: $433-437$

\footnotetext{
* See Appendix: The EPAGE II Study Group
}

19 Nusko G, Mansmann U, Kirchner T, Hahn EG. Risk related surveillance following colorectal polypectomy. Gut 2002; 51: 424-428

20 Winawer SJ, Zauber AG, O'Brien MJ et al. Randomized comparison of surveillance intervals after colonoscopic removal of newly diagnosed adenomatous polyps. The National Polyp Study Workgroup. N Engl J Med 1993; 328: 901 - 906

21 Bertario L, Russo A, Sala P et al. Predictors of metachronous colorectal neoplasms in sporadic adenoma patients. Int J Cancer 2003; 105: 82 87

22 Martinez ME, Sampliner R, Marshall JR et al. Adenoma characteristics as risk factors for recurrence of advanced adenomas. Gastroenterology 2001; 120: $1077-1083$

23 Yang G, Zheng W, Sun QR et al. Pathologic features of initial adenomas as predictors for metachronous adenomas of the rectum. J Natl Cancer Inst 1998; 90: 1661 - 1665

24 Robertson DJ, Greenberg ER, Beach $M$ et al. Colorectal cancer in patients under close colonoscopic surveillance. Gastroenterology 2005; 129: $34-41$

25 Yamaji Y, Mitsushima T, Ikuma $\mathrm{H}$ et al. Incidence and recurrence rates of colorectal adenomas estimated by annually repeated colonoscopies on asymptomatic Japanese. Gut 2004; 53: 568 - 572

26 Saini SD, Kim HM, Schoenfeld P. Incidence of advanced adenomas at surveillance colonoscopy in patients with a personal history of colon adenomas: a meta-analysis and systematic review. Gastrointest Endosc 2006; 64: 614-626

27 O'Brien M, J, Winawer SJ, Zauber AG et al. Flat adenomas in the National Polyp Study: is there increased risk for high-grade dysplasia initially or during surveillance? Clin Gastroenterol Hepatol 2004; 2: 905-911

28 Park DH, Kim HS, Kim WH et al. Clinicopathologic characteristics and malignant potential of colorectal flat neoplasia compared with that of polypoid neoplasia. Dis Colon Rectum 2008; 51: 43 - 49; discussion 49

29 Rembacken BJ, Fujii T, Cairns A et al. Flat and depressed colonic neoplasms: a prospective study of 1000 colonoscopies in the UK. Lancet 2000; 355: 1211-1214

30 Saitoh Y, Waxman I, West AB et al. Prevalence and distinctive biologic features of flat colorectal adenomas in a North American population. Gastroenterology 2001; 120: 1657-1665

31 Soetikno RM, Kaltenbach T, Rouse RV et al. Prevalence of nonpolypoid (flat and depressed) colorectal neoplasms in asymptomatic and symptomatic adults. JAMA 2008; 299: 1027-1035

32 Jass JR, Sobin LH. Histological typing of intestinal tumours. World Health Organization. International histological classification of tumours. Berlin: Springer Verlag, 1989

33 Kronborg O, Jorgensen OD, Fenger $C$, Rasmussen $M$. Three randomized long-term surveillance trials in patients with sporadic colorectal adenomas. Scand J Gastroenterol 2006; 41: 737-743

34 Lund JN, Scholefield JH, Grainge MJ et al. Risks, costs, and compliance limit colorectal adenoma surveillance: lessons from a randomised trial. Gut 2001; 49: 91 -96

35 Brenner H, Chang-Claude J, Seiler CM et al. Case-control study supports extension of surveillance interval after colonoscopic polypectomy to at least 5 yr. Am J Gastroenterol 2007; 102: 1739-1744

36 Laiyemo AO, Murphy G, Albert PS et al. Postpolypectomy colonoscopy surveillance guidelines: predictive accuracy for advanced adenoma at 4 years. Ann Inter Med 2008; 148: 419-426

37 Citarda F, Tomaselli G, Capocaccia $R$ et al. Efficacy in standard clinical practice of colonoscopic polypectomy in reducing colorectal cancer incidence. Gut 2001; 48: $812-815$

38 Jorgensen $O D$, Kronborg O, Fenger C, Rasmussen M. Influence of longterm colonoscopic surveillance on incidence of colorectal cancer and death from the disease in patients with precursors (adenomas). Acta Oncol (Stockholm, Sweden) 2007; 46: 355-360

39 Loeve F, van Ballegooijen M, Boer $R$ et al. Colorectal cancer risk in adenoma patients: a nation-wide study. Int J Cancer 2004; 111: 147-151

40 Loeve F, van Ballegooijen M, Snel P, Habbema JD. Colorectal cancer risk after colonoscopic polypectomy: a population-based study and literature search. Eur J Cancer 2005; 41: 416-422

41 Murakami R, Tsukuma H, Kanamori S et al. Natural history of colorectal polyps and the effect of polypectomy on occurrence of subsequent cancer. Int J Cancer 1990; 46: 159-164

42 Thiis-Evensen E, Hoff GS, Sauar J et al. Population-based surveillance by colonoscopy: effect on the incidence of colorectal cancer. Telemark Polyp Study I. Scand J Gastroenterol 1999; 34: 414-420 
43 ANAES (French National Agency for Accreditation and Evaluation in Healthcare). Indications for lower gastrointestinal endoscopy (excluding population screening). 2004

44 Atkin WS, Saunders BP. Surveillance guidelines after removal of colorectal adenomatous polyps. Gut 2002; 51 Suppl 5: V6 - V9

45 Australian Cancer Network Colorectal Cancer Guidelines Revision Committee. Guidelines for the prevention, early detection and management of colorectal cancer. Sydney: The Cancer Council Australia and Australian Cancer Network, 2005

46 New Zealand Guidelines Group (NZGG). Surveillance and management of groups at increased risk of colorectal cancer. 2004. www.nzgg.org. nz/guidelines/dsp_guideline_popup.cfm?\&guidelineID=48 (accessed 19.2.2008)

47 Scottish Intercollegiate Guidelines Network (SIGN). Management of colorectal cancer: a national clinical guideline. 2003. www.guideline. gov/summary/summary.aspx?doc_id=3724 (accessed 19.2. 2008)

48 Winawer SJ, Zauber AG, Fletcher RH et al. Guidelines for colonoscopy surveillance after polypectomy: a consensus update by the US MultiSociety Task Force on Colorectal Cancer and the American Cancer Society. CA Cancer J Clin 2006; 56: 143 - 159; quiz 184-145

49 Jass JR, Burt R. Hyperplastic polyposis. In: Hamilton SR, Aaltonen LA (eds) WHO International Classification of Tumors: Pathology and genetics of tumors of the digestive system. Berlin: Springer-Verlag, 2000: 135 - 136

50 Walsh RM, Ackroyd FW, Shellito PC. Endoscopic resection of large sessile colorectal polyps. Gastrointest Endosc 1992; 38: 303 - 309

51 Rex DK, Bond JH, Winawer S et al. Quality in the technical performance of colonoscopy and the continuous quality improvement process for colonoscopy: recommendations of the U.S. Multi-Society Task Force on Colorectal Cancer. Am J Gastroenterol 2002; 97: 1296-1308

52 Lautenbach E, Forde KA, Neugut AI. Benefits of colonoscopic surveillance after curative resection of colorectal cancer. Ann Surg 1994; 220: $206-211$

53 Guyot F, Faivre J, Manfredi S et al. Time trends in the treatment and survival of recurrences from colorectal cancer. Ann Oncol 2005; 16: 756 761

54 Kjeldsen BJ, Kronborg O, Fenger C, Jorgensen OD. A prospective randomized study of follow-up after radical surgery for colorectal cancer. Br J Surg 1997; 84: 666-669

55 Barkin JS, Cohen ME, Flaxman $M$ et al. Value of a routine follow-up endoscopy program for the detection of recurrent colorectal carcinoma. Am J Gastroenterol 1988; 83: 1355 - 1360

56 Kronborg 0 . Optimal follow-up in colorectal cancer patients: what tests and how often? Sem Surg Oncol 1994; 10: 217-224

57 Barrier A, Houry S, Huguier M. The appropriate use of colonoscopy in the curative management of colorectal cancer. Int J Colorect Dis 1998; 13: $93-98$

58 Castells A, Bessa X, Daniels M et al. Value of postoperative surveillance after radical surgery for colorectal cancer: results of a cohort study. Dis Colon Rectum 1998; 41: 714-723; discussion 723-714

59 Cubiella J, Gomez R, Sanchez E et al. Endoscopic follow-up of patients after curative surgery for colorectal cancer: results of a medical assistance protocol. Rev Esp Enferm Dig 2003; 95: 278 - 281, 273-277

60 Cuquerella J, Orti E, Canelles $P$ et al. [Colonoscopic follow-up of patients undergoing curative resection of colorectal cancer]. Gastroenterol Hepatol 2001; 24: $415-420$

61 Green RJ, Metlay JP, Propert $K$ et al. Surveillance for second primary colorectal cancer after adjuvant chemotherapy: an analysis of Intergroup 0089. Ann Int Med 2002; 136: 261 - 269

62 Grossmann EM, Johnson FE, Virgo KS et al. Follow-up of colorectal cancer patients after resection with curative intent - the GILDA trial. Surg Oncol 2004; 13: 119-124

63 Lan YT, Lin JK, Li AF et al. Metachronous colorectal cancer: necessity of post-operative colonoscopic surveillance. Int J Colorectal Dis 2005; 20 : $121-125$

64 Mathew J, Saklani AK, Borghol M. Surveillance colonoscopy in patients with colorectal cancer: how often should we be doing it? Surgeon 2006; 4: 3-5, 62

65 McFall MR, Woods WG, Miles WF. Colonoscopic surveillance after curative colorectal resection: results of an empirical surveillance programme. Colorect Dis 2003; 5: $233-240$

66 Platell C, Salama P, Barwood N, Makin G. Performing a colonoscopy 12 months after surgery for colorectal neoplasia. ANZ J Surg 2005; 75: $282-285$
67 Rulyak SJ, Lieberman DA, Wagner EH, Mandelson MT. Outcome of follow-up colon examination among a population-based cohort of colorectal cancer patients. Clin Gastroenterol Hepatol 2007; 5: 470-476; quiz 407

68 Schoemaker D, Black R, Giles L, Toouli J. Yearly colonoscopy, liver CT, and chest radiography do not influence 5-year survival of colorectal cancer patients. Gastroenterology 1998; 114: 7 - 14

69 Skaife P, Seow-Choen F, Eu KW, Tang CL. A novel indicator for surveillance colonoscopy following colorectal cancer resection. Colorect Dis 2003; 5 : $45-48$

70 Stigliano V, Fracasso P, Grassi A et al. Endoscopic follow-up in resected colorectal cancer patients. J Exp Clin Cancer Res 2000; 19: 145-148

71 Togashi K, Konishi F, Ozawa A et al. Predictive factors for detecting colorectal carcinomas in surveillance colonoscopy after colorectal cancer surgery. Dis Colon Rectum 2000; 43: S47 - 53

72 Yusoff IF, Hoffman NE, Ee HC. Colonoscopic surveillance after surgery for colorectal cancer. ANZ J Surg 2003; 73: 3 -7

73 Bouvier AM, Latournerie M, Jooste V et al. The lifelong risk of metachronous colorectal cancer justifies long-term colonoscopic follow-up. Eur J Cancer 2008; 44: 522-527

74 Adloff M, Arnaud JP, Ollier JC, Schloegel M. [Can the prognosis of patients treated surgically in cancer of the rectum or colon be improved by follow-up? Prospective study of 909 patients]. Chirurgie; memoires de l'Academie de chirurgie 1989; 115: 228 - 236; discussion 236-227

75 Barillari P, Ramacciato G, Manetti G et al. Surveillance of colorectal cancer: effectiveness of early detection of intraluminal recurrences on prognosis and survival of patients treated for cure. Dis Colon Rectum 1996; 39: 388 - 393

76 Richard CS, McLeod RS. Follow-up of patients after resection for colorectal cancer: a position paper of the Canadian Society of Surgical Oncology and the Canadian Society of Colon and Rectal Surgeons. Can J Surg 1997; 40: 90 - 100

77 Rodriguez-Moranta F, Salo J, Arcusa A et al. Postoperative surveillance in patients with colorectal cancer who have undergone curative resection: a prospective, multicenter, randomized, controlled trial. J Clin Oncol 2006; 24: 386-393

78 Sargent DJ, Wieand HS, Haller DG et al. Disease-free survival versus overall survival as a primary end point for adjuvant colon cancer studies: individual patient data from 20898 patients on 18 randomized trials. J Clin Oncol 2005; 23: 8664-8670

79 Secco GB, Fardelli R, Gianquinto D et al. Efficacy and cost of risk-adapted follow-up in patients after colorectal cancer surgery: a prospective, randomized and controlled trial. Eur J Surg Oncol 2002; 28: 418-423

80 Galandiuk S, Wieand HS, Moertel CG et al. Patterns of recurrence after curative resection of carcinoma of the colon and rectum. Surg Gynecol Obstet 1992; 174: $27-32$

81 Kjeldsen BJ, Kronborg O, Fenger C, Jorgensen OD. The pattern of recurrent colorectal cancer in a prospective randomised study and the characteristics of diagnostic tests. Int J Colorectal Dis 1997; 12: 329 - 334

82 Tornqvist A, Ekelund G, Leandoer $L$. The value of intensive follow-up after curative resection for colorectal carcinoma. Br J Surg 1982; 69: $725-728$

83 Harris GJ, Church JM, Senagore AJ et al. Factors affecting local recurrence of colonic adenocarcinoma. Dis Colon Rectum 2002; 45: 1029 1034

84 Manfredi S, Benhamiche AM, Meny B et al. Population-based study of factors influencing occurrence and prognosis of local recurrence after surgery for rectal cancer. Br J Surg 2001; 88: 1221 - 1227

85 Manfredi S, Bouvier AM, Lepage C et al. Incidence and patterns of recurrence after resection for cure of colonic cancer in a well defined population. Br J Surg 2006; 93: 1115-1122

86 Obrand DI, Gordon PH. Incidence and patterns of recurrence following curative resection for colorectal carcinoma. Dis Colon Rectum 1997; 40: $15-24$

87 Fajobi O, Yiu CY, Sen-Gupta SB, Boulos PB. Metachronous colorectal cancers. Br J Surg 1998; 85: 897 - 901

88 Gervaz P, Bucher P, Neyroud-Caspar I et al. Proximal location of colon cancer is a risk factor for development of metachronous colorectal cancer: a population-based study. Dis Colon Rectum 2005; 48: 227 - 232

89 Froehlich F, Gonvers JJ. Diagnostic yield of colonoscopy by indication. In: Waye JD, Rex DK, Williams CB, (eds) Colonoscopy: principles and practice. Oxford: Blackwell Publishing, 2003: 111

90 Rex DK, Kahi CJ, Levin B et al. Guidelines for colonoscopy surveillance after cancer resection: a consensus update by the American Cancer So- 
ciety and the US Multi-Society Task Force on Colorectal Cancer. Gastroenterology 2006; 130: 1865-1871

91 Ramsey SD, Howlader N, Etzioni $R$ et al. Surveillance endoscopy does not improve survival for patients with local and regional stage colorectal cancer. Cancer 2007; 109: 2222 - 2228

92 Fisher DA, Jeffreys A, Grambow SC, Provenzale D. Mortality and followup colonoscopy after colorectal cancer. Am J Gastroenterol 2003; 98 : 901-906

93 Pietra N, Sarli L, Costi R et al. Role of follow-up in management of local recurrences of colorectal cancer: a prospective, randomized study. Dis Colon Rectum 1998; 41: 1127-1133

94 Makela JT, Laitinen SO, Kairaluoma MI. Five-year follow-up after radical surgery for colorectal cancer. Results of a prospective randomized trial. Arch Surg 1995; 130: 1062 - 1067

95 Ohlsson B, Breland U, Ekberg $\mathrm{H}$ et al. Follow-up after curative surgery for colorectal carcinoma. Randomized comparison with no follow-up. Dis Colon Rectum 1995; 38: 619-626

96 Figueredo A, Rumble RB, Maroun J et al. Follow-up of patients with curatively resected colorectal cancer: a practice guideline. BMC Cancer 2003; $3: 26$

97 Jeffery $M$, Hickey BE, Hider PN. Follow-up strategies for patients treated for non-metastatic colorectal cancer. Cochrane database of systematic reviews (Online) 2007; CD002200:

98 Kievit J. Follow-up of patients with colorectal cancer: numbers needed to test and treat. Eur J Cancer 2002; 38: 986 -999

99 Renehan AG, Egger M, Saunders MP, O'Dwyer ST. Impact on survival of intensive follow up after curative resection for colorectal cancer: systematic review and meta-analysis of randomised trials. BMJ (Clinical research ed) 2002; 324: 813

100 Tjandra JJ, Chan MK. Follow-up after curative resection of colorectal cancer: a meta-analysis. Dis Colon Rectum 2007; 50: 1783 - 1799

101 Anthony T, Simmang C, Hyman N et al. Practice parameters for the surveillance and follow-up of patients with colon and rectal cancer. Dis Colon Rectum 2004; 47: 807-817

102 Association of Coloproctology of Great Britain and Ireland. Guidelines for the management of colorectal cancer. London: The Association of Coloproctology of Great Britain and Ireland, 2007

103 Desch CE, Benson AB 3rd, Somerfield MR et al. Colorectal cancer surveillance: 2005 update of an American Society of Clinical Oncology practice guideline. J Clin Oncol 2005; 23: 8512-8519

104 Tveit KM, Kataja VV. ESMO minimum clinical recommendations for diagnosis, treatment and follow-up of rectal cancer. Ann Oncol 2005; 16 Suppl 1: i20 - i21

105 VanCutsem EJ, Kataja VV. ESMO minimum clinical recommendations for diagnosis, adjuvant treatment and follow-up of colon cancer. Ann Oncol 2005; 16 Suppl 1: i16-i17

106 Lanza E, Yu B, Murphy G et al. The Polyp Prevention Trial continued follow-up study: no effect of a low-fat, high-fiber, high-fruit, and -vegetable diet on adenoma recurrence eight years after randomization. Cancer Epidemiol Biomarkers Prev 2007; 16: 1745-1752

107 Benamouzig R, Deyra J, Martin A et al. Daily soluble aspirin and prevention of colorectal adenoma recurrence: one-year results of the APACC trial. Gastroenterology 2003; 125: 328 - 336

108 Fossi S, Bazzoli F, Ricciardiello L et al. Incidence and recurrence rates of colorectal adenomas in first-degree asymptomatic relatives of patients with colon cancer. Am J Gastroenterol 2001; 96: 1601 - 1604
109 Gandhi SK, Reynolds MW, Boyer JG, Goldstein JL. Recurrence and malignancy rates in a benign colorectal neoplasm patient cohort: results of a 5-year analysis in a managed care environment. Am J Gastroenterol 2001; 96: $2761-2767$

110 Blumberg D, Opelka FG, Hicks TC et al. Significance of a normal surveillance colonoscopy in patients with a history of adenomatous polyps. Dis Colon Rectum 2000; 43: 1084 - 1091; discussion 1091-1082

111 Schatzkin A, Lanza E, Corle D et al. Lack of effect of a low-fat, high-fiber diet on the recurrence of colorectal adenomas. Polyp Prevention Trial Study Group. N Engl J Med 2000; 342: 1149-1155

112 Baron JA, Beach M, Mandel JS et al. Calcium supplements for the prevention of colorectal adenomas. Calcium Polyp Prevention Study Group. N Engl J Med 1999; 340: 101 - 107

113 van Stolk RU, Beck GJ, Baron JA, Haile R, Summers R. Adenoma characteristics at first colonoscopy as predictors of adenoma recurrence and characteristics at follow-up. The Polyp Prevention Study Group. Gastroenterology 1998; 115: $13-18$

114 Jorgensen $O D$, Kronborg $O$, Fenger $C$. The Funen Adenoma Follow-up Study. Incidence and death from colorectal carcinoma in an adenoma surveillance program. Scand J Gastroenterol 1993; 28: 869-874

115 Gastrointestinal Cancer Disease Site Group. Figueredo A, Rumble RB, Maroun J et al. Follow-up of patients with curatively-resected colorectal cancer (full report). Cancer Care Ontario (CCO) 2004; Practice Guideline Report 2-9

The following figures and tables are available online: www.thieme-connect.com/media/endoscopy/200903/supmat/ endo847.pdf

Fig. e1 Colonoscopic surveillance in asymptomatic people after adenoma removal. Other considerations include age, comorbidity, and family history.

Fig. e2b Appropriateness ratings of clinical indications for performing colonoscopy for surveillance after polypectomy (full decision tree).

Fig. e3b Appropriateness ratings of clinical indications for performing colonoscopy for surveillance after curative-intent resection of colorectal cancer (CRC) (full decision tree).

Table e1 Diagnostic yield of surveillance colonoscopy after polypectomy.

Table e2 Risk factors at baseline colonoscopy for advanced adenomas at surveillance colonoscopy.

Table e3 Impact of polypectomy and colonoscopic surveillance on colorectal cancer (CRC) incidence and mortality.

Table e4 Guidelines for colonoscopy surveillance after polypectomy. Table e5 Diagnostic yield of colonoscopy surveillance programs after curative resection of colorectal cancer (CRC).

Table e6 a Local recurrence rates of colorectal cancer (CRC) according to primary tumor stage (5-year overall rate). b Cancer classifications. c Tumor-node-metastasis (TNM) definitions.

Table e7 Randomized controlled trials (RCTs) of surveillance followup programs after colorectal cancer (CRC) surgery.

Table e8 Guidelines on surveillance colonoscopy after curative intent resection of colorectal cancer (CRC). 